\title{
DOCUMENTOS
}

\section{La Correspondencia entre José Enrique Rodó y Juan Ramón Jiménez}

Ariel, escrito para América, y en especial para la juventud de América, es uno de los libros que mejor expresa la inquietud y el idealismo de los jóvenes que iniciaban su labor intelectual y literaria en las primeras décadas del siglo xx en Hispanoamérica. En Ariel encontraron apoyo moral y cultural millares de jóvenes hispanoamericanos. Tal fue la difusión de su ideología que dio origen a un vocablo nuevo, arielismo, con el cual quedó indentificada toda una generación de hispanoamericanos.

Dado el valor intrínseco de la obra de Rodó, y la oportunidad de su mensaje, no es de extrañarse que los hispanoamericanos la acogieran con entusiasmo. Lo que sí podría ser motivo de sorpresa es la reacción inmediata y entusiasta que produjo Ariel entre los escritores de España, sobre todo los jóvenes, peto también entre algunos de los más maduros y conocidos. ${ }^{1}$ Apenas publicado Ariel, apareció en una de las revistas culturales

1 Clarín elogia sin reserva el libro de Rodó, como se ve en el párrafo siguiente que resume su comentario:

Ariel aconseja a la juventud hispanolatina que no se deje seducir por la sirena del Norte; el ideal clásico y el ideal cristiano deben guiarla, sin que deje de ser moderna, progresiva. Como se ve, lo que Rodó pide a los americanos latinos es que sean siempre... lo que son, es decir, españoles, hijos de la vida clásica y de la cristiana. Citado por Hugo D. Barbagelata, Rodó y sus críticos, París, 1920, p. 49. 
más prestigiosas de España, La España moderna, ${ }^{2}$ un artículo sobre el libro de Rodó, escrito por Emilio Gómez de Baquero. El crítico español comenta la obra del escritor uruguayo y la elogia por sus sanos principios y su elevada expresión:

Es éste uno de los escritos más elocuentes que ha producido la inspiración literaria en la América moderna, y en él se advierte una madurez de pensamiento, un equilibrio estético y un espiritu de continuidad con la tradición literaria y la tradición filosófica europeas, que pocas veces hallamos en los escritores del Nuevo Mundo. ${ }^{3}$

El momento era propicio para la introducción en España del pensamiento de Rodó. La presencia de Rubén Dario en España en aquella época ${ }^{4}$ contribuyó mucho, sin duda, a que la juventud de ese país volviera los ojos hacia América en espera de otro estímulo literatio. Además, los vínculos entre España y sus antiguas dependencias parecían afirmarse después de la tragedia de 1898 y la pérdida de las últimas colonias americanas. Lo que Rodó contribuyó a la orientación espiritual y estética de la juventud española de esta época lo expresa Martínez Sierra en un ensayo escrito hacia $1905 .^{\circ}$ Comienza así:

... Es incalculable todo el bien que en no pocas almas de la España joven ha causado ese libro pequeño que lleva el nombre de aquel espiritu del aire a quien Shakespeare quiso hacer inspirador del bien, servidor pronto y alegre de la vieja ciencia de Próspero.6

Entre los escritores de esa "España joven", uno de los más fervoro-

Unamuno, siempre sobre aviso cuando se trataba de descubrir tendencias hacia el afrancesamiento desmedido, aplaude el acierto de Rodó en establecer cierto equilibrio y armonía entre el pensamiento francés y la tradición hispánica: "... Es una honda traducción al castellano -no sólo al lenguaje sino al espíritu - de lo que el alma francesa tiene de ateniense y de más elevado." Rodó y sus criticos, p. 50.

Juan Valera, amable y bondadoso por lo común en su crítica, es, tal vez, el más acerbo de los críticos de Rodó. Opina que el ensayista uruguayo ha sido injusto con los Estados Unidos, pero lo que más le desagrada es el desapego de Rodó frente a España: ". . en su libro hay algo que me apesadumbra: el olvido de la antigua madre patria, de la casta y de la civilización de que procede la América que se empeña en llamar latina. Rodó y sus criticos, p. 54.

2 Guillermo Díaz Plaja califica esta revista de "excelente" y el trabajo cultural de sus editores de "asombroso". Modernismo frente a noventa y ocho, Madrid, 1951, págs. 18-19.

3 Emilio Gómez de Baquero, "Crónica literaria", La España moderna, Madrid, junio de 1900 , p. 127.

4 Darío había llegado a España el primero de enero de 1899 y se quedó alli hasta la primavera de 1900.

5 Gregorio Martínez Sierra, Motivos, Madrid, 1920, p. 87.

6 Martínez Sierra, op. cit., p. 89. 
sos en su admiración por Rodó, era Juan Ramón Jiménez. El poeta andaluz, al igual que su amigo Martínez Sierra y otros de sus contemporáneos, nombraban a Ariel entro sus libros predilectos:

Una misteriosa actividad nos cogía a algunos jóvenes españoles cuando hacia 1900 se nombraba en nuestras reuniones a Rodó. Ariel, en su único ejemplar conocido pot nosotros, andaba de mano en mano sorprendiéndonos. ¡Qué ilusión entonces para mi deseo poseer aquellos tres libritos delgados, azules, pulcros, de letra nítida roja y negra: Ariel, Rubén Dario, El que vendrál 7

Pasaton muchos años sin que Juan Ramón Jiménez llegara a ver a su "amigo lejano", pero a pesar del tiempo y de la distancia que los separaban no se enfrió su amistad. ${ }^{8}$ Con los libros que se mandaban, uno al otro, y con las cartas que se escribian pudieron mantener una comunicación viva y cordial. En su archivo personal Juan Ramón Jiménez conservaba cartas de Rodó. ${ }^{9}$ Varias son las cartas o notas que él escribió al maestro uruguayo. La correspondencia entre los dos escritores nunca fue copiosa pero da testimonio de una amistad sincera y duradera. ${ }^{10}$ Se inicia con la carta siguiente de Juan Ramón Jiménez:

Primera carta de Juan Ramón Jiménez

Sr. D. José Enrique Rodó

I/I902.

Maestro:

Tengo el placer de remitir a usted por este correo un ejemplar de mi libro Rimas que acaba de salir a luz. Yo agradeceré a usted con toda mi alma que me escriba diciéndome su más sincera opinión sobre esos pobres versos. Al mismo tiempo le ruego que me remita sus libros, pues aunque los he leido y releído, no tengo el gusto de poseerlos. 62.

7 Juan Ramón Jiménez, Españoles de tres mundos, Buenos Aires, 1942, p.

8 Rodó y Juan Ramón Jiménez se vieron sólo una vez, en 1917. Poco después de la breve visita que le hizo al poeta español, en Madrid, Rodó salió para Italia. Allí le sorprendió la muerte el primero de mayo de 1917.

9 Algunas de las cartas se extraviason. Este epistolario no pretende ser completo. Véase la nota 14.

;0 Algunas de las cartas que Juan Ramón Jiménez le escribió a Rodó fueron devueltas al poeta por amigos uruguayos en 1948. En aquel año Jiménez, acompañado por su esposa, visitó Buenos Aires y Montevideo. 
Le pongo estas líneas para saludarlo y para of recerme a usted como servidor y amigo; quisiera ser extenso pero mi anemia no lo consiente $\mathrm{y}$ tengo votos porque usted no sepa en toda su vida que la enfermedad es la amante más celosa y más constante. ${ }^{11}$

Aquí me tiene -en este sanatorio ${ }^{\mathrm{J} 2}$ por ahora- a su completa disposición. Espero su carta y sus libros y le envío mi admiración y mi gratitud.

JUAN R. JIMÉNEZ.

\author{
S/C. Sanatorio del Rosario \\ Príncipe de Vergara I4 \\ Madrid
}

Segunda carta ${ }^{13}$ de Juan Ramón Jiménez

Sr. D. José Entique Rodó

Ilustre maestro: recibí su cariñosa carta ${ }^{14}$ y no le he escrito antes esperando que llegara también el ejemplar de Ariel que me anunciaba; aún no ha llegado $\mathrm{y}$, creyéndolo perdido, me decido a escribirle para darle un millón de gracias por el libro-que tan mala suerte ha hallado-y por su hermosa carta que es para mí un bálsamo y una palabra amorosa. Usted, querido maestro, me ha proporcionado con sus líneas una infinita satisfacción, porque salvando esa inmensa distancia que nos separa sobre la tierra, ha visto usted a mi alma como es y ha oído de muy cerca el llanto de mis pobres versos, hasta el extremo de creer yo que su carta es la conversación de un amigo de mucho tiempo. Yo quisiera que no me olvidara usted en su correspondencia, y que, cuando tuviera, después de hacerlo todo, un rato de lugar, me pusiera sobre el papel palabras de esas que usted sabe imbuir de espíritu y de arte, en la seguridad

I:1 Jiménez había pasado más de la mitad del año 1901 en un sanatorio de Burdeos. Cuando escribió esta carta su salud no estaba enteramente restablecida.

12 Se trata del Sanatorio del Rosario de Madrid, refugio de Jiménez en 1902 y 1903.

13 Esta carta no tiene fecha, pero como lleva la dirección del Sanatorio del Rosario, se puede asentar que es de 1902 ó 1903.

14 La carta a la cual se refiere Juan Ramón comenta su libro Rimas publicado en 1902. Esta carta de Rodó, así como dos cartas muy breves del poeta español, fueron reproducidas en la revista Marcba de Montevideo, el 25 de junio de 1954, con un comentario por Emit Rodríguez Monegal. 
de que tendrá en mi cerebro y en mi corazón nidos calientes y llenos de gratitud. $Y$ no me olvide cuando publique algo, tampoco.

Créame un admirador constante y un verdadero amigo.

JUAN R. JIMÉNEZ.

Madrid

S. C. Sanatorio del Rosario

Príncipe de Vergara I4

Tercera carta de Juan Ramón Jiménez

Sr. D. José Enrique Rodó

Querido maestro: Agustín Querol, Martínez Sierra, tres amigos más y yo, ${ }^{15}$ vamos a hacer una revista seria y fina. Un tomo mensual de 150 páginas de literatura selecta, nada de dinero; nosotros mismos pagamos la revista. Sólo le diré: es una cosa muy seria.

Nosotros agradeceremos a usted infinitamente que nos remitiera, cuando buenamente pudiese, algún trabajo de cualquier asunto-dimensiones a gusto de usted - tendencia, etc. ${ }^{16}$

El número primero saldrá el $I^{9}$ de abril. ${ }^{17}$-Supongo en su poder mi última carta.

Le admira y le quiere su amigo verdadero.

JUAN R. JIMÉNEZ.

Sanatorio del Rosario

Príncipe de Vergara I4. Madrid

Cuarta carta ${ }^{18}$ de Juan Ramón Jiménez

Querido maestro: he recibido su tarjeta y el ejemplar de Ariel que

15 Los otros fundadores de la revista Helios eran Agustín Querol, Ramón Pérez de Ayala y Pedro González Blanco. Jiménez ya había escrito una carta a Rubén Darío pidiéndole su colaboración.

16 Helios nunca llegó a publicar un trabajo de Rodó.

17 Salió en efecto, como Juan Ramón habia prometido. Sólo once números fueron publicados.

18 Esta carta no tiene fecha pero por su contenido se ve que fue escrita en 1903 después del mes de abril. 
le agradezco verdaderamente. Un millón de gracias también por cuanto me promete; supongo que habrá usted recibido el primer número de Helios. ¿Qué le parece? Martínez Sierra recibió su carta; me dice que escribirá a usted, largamente; también di sus recuerdos a Pellicer. ${ }^{19}$ No nos olvide, querido maestro, y mande cuanto quiera a su verdadero admirador.

JUAN R. JIMÉNEZ.

\author{
S/C. Sanatorio del Rosario

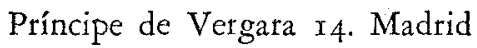 \\ Primera carta de José Enrique Rodó \\ Montevideo, to de julio de 1904 \\ Sr. J. R. Jiménez \\ Madrid
}

Pocta y amigo: Pronto irá a visitar a Ud. en mi nombre un compatriota mío-Juan Francisco Piquet ${ }^{20}$ - que está actualmente en Barcelona. Êl le dirá cuán amistosamente le recuetdo a Ud. siempre y con qué sinceto aplauso sigo la valiente labor de Uds. en las páginas, cada vez más interesantes, de Helios.

El objeto de ésta es anunciarle la visita de dicho amigo. No atribuya Ud. mi largo silencio a olvido, ni mi laconismo a falta de voluntad. En la agitación política que aquí nos arrebata a todos, dispongo de poco ticmpo para las cosas del espíritu.

Déme Ud. nuevas de sus proyectos literarios. Sé que publicó Ud. un libro pero no he tenido la dicha de vetlo. En cuanto a mí, publicaré quizá dentro de pocos meses, mi nueva obra Proteo. ${ }^{21}$ Será extensa y cifro en ella algunas esperanzas.

Salude Ud. en mi nombre al brillante y esforzado grupo de $\mathrm{He}$ lios y créame siempre su amigo muy sincero.

\title{
José EnRrque Rodó
}

19 Se trata, al parecer, de Julio Pellicer, otro de los colaboradores en la revista Helios.

20 Juan Ramón Jiménez no menciona en ninguna parte al amigo de Rodó, de manera que no se puede precisar si la visita llegó a hacerse.

21. Los motivos de Proteo fue publicado en Montevideo en 1909 aunque Rodó había escrito ya (1904) parte del libro. 
Cerrito I023

Carta de Eustaquio Jiménez, hermano de Juan Ramón Jiménez a José Enrique Rodó

Sr. D. José Enrique Rodó

Moguer ${ }_{17}$ Novbre 1908 Montevideo

Muy Sr. mío: Sabiendo por mi hermano Juan Ramón que es V. buen amigo suyo, me permito molestarlo para rogarle que estando vacante en Huelva el Consulado de esa República recomiende V. que ese nombramiento sea hecho para mi.

En estos dias se proyectan celcbrar para el año próximo unas regatas y una exposición de esas Repúblicas para estrechar nuestras relaciones con las mismas y sería muy conveniente que esa importante República tuviera su consulado.

Dispénseme y aprovecho gustoso esta ocasión para ofrecerme su más atto. S. S. Q. S. M.

\section{EUSTAQUIo JIMÉNEZ ${ }^{22}$}

Quinta carta ${ }^{23}$ de Juan Ramón Jiménez a José Enrique Rodó

Mi querido maestro:

Tengo un verdadero interés en que usted haga cuanto le sea posible por conseguirle a mi hermano lo que desea.

¿Qué de tiempo sin saber de usted! Hace unos días le he mandado mis Elegias puras. ${ }^{24}$ Pienso dar una serie de tomitos de ese tamaño con todo lo que tengo hecho. Y su Proteo?25

Le escribiré más detenidamente. Hoy, reciba la verdadera admira. cinó y el cariño de su amigo.

\section{J. R. JIMÉNEZ.}

22 Eustaquio Jiménez era mayor que Juan Ramón. No fue hombre de letras.

23 Sin fecha pero escrita, probablemente, en 1908.

214 Publicadas en la Tipografía de la Revista de Archivos, Madrid, 1908.

25 Véase la nota 21. 
Sexta carta ${ }^{26}$ de Juan Ramón Jiménez a José Enrique Rodó

Querido maestro:

Acabo de recibir sus Motivos de Proteo y me apresuro a enviarle estas palabras de agradecimiento. Después de tantos días de recuerdo y de cariño. Nadie como yo le admira; y, sin embargo, por esta enorme enfermedad de la voluntad que me cortoe, pasan meses y años sin decirle todo lo que quisicra. Intentaré ordenar en una revista las múltiples consideraciones que me sugiere su personalidad; esta carta es sólo un ramo de cariño. - Ahí van esos dos libros que he publicado recientemente-; preparo una edición de todo lo mío-r4 tomos-, que pienso empezar a dar en otoño; 27 ya le llenaré las manos de libros. Y quiero anticiparle que La soledad sonora tiene en su primera página el nombre de usted. ${ }^{28}$ ¿Lee usted las revistas literatias de España? Cuando desee algo de por acá, ya sabe que me tiene a su disposición. Usted, en cambio, no me olvide cuando crea que algo pueda serme útil, de lo de por ahí, pues yo soy de los pocos poetas españoles que cultivan su inteligencia. Y escríbame con frecuencia.

Su amigo, que le admira fervorosamente.

Moguer 29

J. R. JIMÉNEZ.

Segunda carta de José Enrique Rodó a Juan Ramón Jiménez

Montevideo, I7 de septiembre de r909

Sr. D. Juan R. Jiménez.

Moguer.

Poeta y amigo: Bienvenida su cariñosa carta y bienvenidos sus dos últimos libros, ${ }^{30}$ que he leído con suave deleite.

Su poesía es de Ud. en fondo y forma: es su alma misma en la más pura y transparente expresión que un alma pueda darse en palabras.

20 Escrita en 1909.

27 Este proyecto del poeta nunca llegó a cumplirse.

28 Publicada en la Tipografía de la Revista de Archivos, Madrid, 1911.

29 El poeta volvió a Moguer en 1905 y se quedó allí hasta 1912.

30 Rodó habla, al parecer, de Elegías puras y Elegias intermedias. Fueron 
Infunde Ud. de tal manera su espíritu en las condiciones de la forma poética, que nuestro idioma, en sus versos, parece pasar por una verdadera transfiguración. Nunca se le hizo $\tan$ leve, $\tan$ vaporoso, tan alado. Leyendo sus versos se reconoce con sorpresa y arrobamiento, todos los secretos de espiritualidad musical, de vaguedad aérea, que cabe arrancar al genio de una lengua tenida por tan exclusivamente pintoresca y plástica.

Y en la manera como siente Ud. la poesía de las cosas, su personalidad aparece, igualmente, aislada y como nostílgica en su medio. "-Dónde está aquí el sol de Andalucía?"-, me preguntaba alguien después de hojear uno de los libros que Ud. me ha enviado. $Y$ en efec. to: el sol que Ud. canta no es el que ven los demás en Andalucia: es el suyo, el que Ud. ve: es el sol velado, melancólico y mustio que difunde sobre los campos su pena de enfermo en una página admitable de las Elegias; el cielo que Ud. refleja no es el de amaranto y oro del soneto de Tassara: el cielo gris que ha dejado para siempre, en el fondo del arroyo "que luego fue su corazón", un fondo de ceniza, en otra página muy bella del mismo libro; los jardines por donde Ud. pasea no son los que visten las márgenes del Betis y el Genil con las pompas triunfales de una primavera inmarcesible: son aquellos a cuyos tristes rosales prestó la paseante de su Elegía XXVI "la gracia melancólica" de sus maneras...

¿Será esto razón para decir que no es Ud. un poeta andaluz? Yo creo que sí lo es y que lo es de la manera más honda. Un ilustre escritor decía, con motivo de El Patio Andaluz de Salvador Rueda, que no hay una sola Andalucía, sino varias... Hay seguramente muchas; pero, por mi parte, yo también sé o sospecho de varias. Hay una que detesto; otra que admiro; otra, muy vagamente sabida, que quiero y me encanta. La que detesto es la de los toros y los majos y la alegría estrepitosa y la gracia de los chascarrillos. La que admiro es la de los poetas sevillanos y los pintores del color, y la naturaleza ebria de luz, y las pasiones violentas e insaciables... Pero la que quiero y me encanta es una que, por muy leves indicios, sospecho que existe: una muy sentimental, muy delicada, muy dulce, como nacida de la fatiga lánguida y melancólica de los desbordes de sangre, de luz y de voluptuosidad de aquella otra Anda-

las Elegías que le movieron a escribir su "Recóndita Andalucía" (1910), donde alude a la poesía de Juan Ramón como "la más limpia y transparente expresión que alma humana pueda darse en palabras", igual que en su carta. El ensayo es uno de los que constituyen el libro El mirador de Próspero. 
lucía, la admirable, la solamente admirable: no la adorable, la divina, la hermética ... Y Ud. es el poeta de esta Andalucía, soñada más que real, y tiene de ella el alma y la voz...

Vuelva a escribirme con frecuencia: hábleme de la juventud española y de lo que ella piensa, sueña y produce.

Espero con vivo interés los nuevos libros que Ud. me anuncia, y quedo de Ud. amigo muy sincero.

\section{José EnRIQue Rodó}

$\mathrm{S} / \mathrm{C} \cdot$ Cerrito 102" $^{4}$

DONALD F. FogeLquist.

Universidad de California,

Los Angeles, Califonnia. 